\title{
Research on the Interaction of Car Online Modification Based on Virtual Display
}

\author{
Chunfu Li \\ The Department of Industrial Design \\ Huazhong university of science and technology \\ Wuhan City, Hubei Province, China \\ 740284247@qq.com
}

\author{
Yangmeng Ke \\ The Department of Industrial Design \\ Huazhong university of science and technology \\ Wuhan City, Hubei Province, China \\ 1589401121@qq.com
}

\author{
Yuhui Wang \\ The Department of Industrial Design \\ Huazhong university of science and technology \\ Wuhan City, Hubei Province, China \\ 346235912@qq.com
}

\begin{abstract}
The thesis propose the interaction design procedures and principles by discourse and compare virtual display , combine with the actual characteristics of interaction design, then base on the virtual display theory. The principles are accuracy, patency, and consistency. Through analyze and apply car online modified examples, the results show that the theories and methods are effective.
\end{abstract}

Keywords-virtual display; interaction design; information architecture; interaction procedure

\section{INTRODUCTION}

Virtualization, namely information technology, reproduces the physical substance in specific digital information in a computer system. It becomes the contemporary physical substance virtualization development trend. Display design virtualization will demonstrate the physical substance content into images, symbols, dynamic behavior, and other information media through virtual technology reproduce image and symbols referring to the physical material objects in the display system[1].

Interaction design is the user's behavior to artifacts, environment and system, as well as convey that the shape elements of such acts design and definitions[2]. Interactive virtual display is a good carrier for interactive design, in recent years, there have many successful applications of interaction design examples, and the technology can provide a good virtual interactive and analog display environment.

Relying on computer and network technology, virtual display is a branch of display design in digitized direction. Therefore, the virtual display design as main bodies which mainly based on the knowledge of the display design, computer and internet skills for technical support, and take use of information technology computing and practical equipment to achieve variety demonstration purposes.

\section{INTERACTIVE DESIGN THEORY BASE ON VIRTUAL DISPLAY}

Because the user's age,cognitive level,different use habits,products shape,color,movement change of virtual display convey display contents will have a significant difference during receive information process. Therefore, the virtual display strategic research is one direction of the interactive form researches[3].

Virtual display display relying on the traditional display showcase strategy, but it has its own characteristics in the actual operation that the display forms of every aspect are included different interactive design patterns[4].

TABLE I. PRESENCES COMPARISON

\begin{tabular}{|c|c|c|}
\hline & Entity Display & Virtual display \\
\hline Present & Graphic display panels & Screen display \\
\hline Expand & Physical amplification & $\begin{array}{c}\text { Model as a whole or partial } \\
\text { image magnification }\end{array}$ \\
\hline Narrow & $\begin{array}{c}\text { Microfilm or dynamic sand } \\
\text { table model }\end{array}$ & $\begin{array}{c}\text { Virtual model as a whole or } \\
\text { part of the scale }\end{array}$ \\
\hline $360^{\circ}$ rotation & Turn booth & Model $360^{\circ}$ rotation \\
\hline Contrast & Environmental foil & Multiple model contrast \\
\hline Additions \\
replacement
\end{tabular}

During the design process, it mixes with different display forms, interactive design principles are as follows:

\section{A. Accuracy principles}

Users is the core of the entire design process throughout the design process, during the design process, it should base on the user's understanding of goals and motivations, accurate 
response user's psychological expectations. It is the cornerstone of the entire design on how to determine user expectations, identify the user's real goal and base on this basis to convey information accurately to the users.

\section{B. Patency principles}

A completely web design includes a range of information, processes and actions, the user mainly focus on web fluency, which including the pages began to enter the page, the user interaction flow in general, certain the function point of the process. Therefore uncertainty of user process need optimize the other flow may occur to users , and in the procedure pages choose which use visual language to express the concept of design form, function and image, etc[5]. It mainly focuses on process design and ignores the small details page with widgets on purpose.

\section{Consistency Principle}

1) Consistent visual elements: Visual design of interactive elements often affects user interaction effect. The same parts of buttons adopt a consistent style of the visual design is a great help in maintaining user habits and improving interactivity. But there is no special balancing method about how to ensure consistent elements appearance and does not because the appearance of elements design becomes silent and dull, therefore after the competition, it needs to investigate the target user or obtain feedback for further improvements.

2) Consistent Interactions: A different type elements which corresponds to the behavior of the user triggers an event or same type interaction elements of behavior caused by the same event, their interactions need to maintain the consistency. For example: All the dialogs that require confirm the operation by users must contain at least two, confirm button and give up button.

D. Design mode

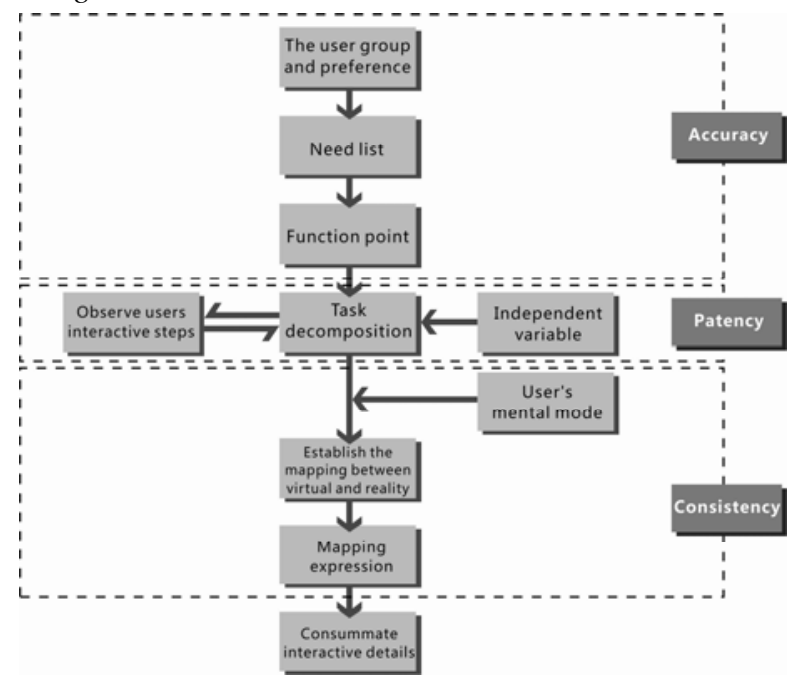

FIGURE I. Interaction design mode of virtual display

Steps are as follows: a) Under the guidance of the accuracy principles to analysis the user groups and preferences. It analyzes the target users systematically mainly take some methods such as questionnaires, data collection, and other ways to be realized.

b) Through analyze the target user summarized list of the user's needs, and prioritize the list of requirements, assess whether it is appropriate and when the demand has to be realized.

c) Analyze the requirements lists; decompose the overall task process, make a number of relatively independent subtasks, observe user operation under the guidance of fluency principle.

d) Analyze the user's steps and actions, and previously divide into sub-tasks, supply and optimize the task flow.

e) Describe the user mental model expression form in the specific layout and details, through the principle of consistency. Analysis and compare the user's mental model and realistic model to find the mapping between the two methods.

f) Apply between the user mental models and reality models mapping to the interface layout and detail design.

\section{CASE STUDY}

Car modification view automobile brand culture as the basic features, the owner's favorite and preference as the trend, with the industrialized fixed models, combine a specific concept car design, take advantage of advanced techniques and technologies, then add a wide range of accessories, personality improve the car's ornamental and functional and make it comply with relevant national regulations and safety standards, ultimately meet the people of the modified car's personality aesthetic, versatile, diverse needs[6].

Recently, the rapid development of the Internet and ecommerce allows people can buy favorite products at home. Automobile manufacturers through a virtual display approach provide a variety of options to solve the limitations problem of auto shops models and quantity.

The result of online modification should present in front of consumers in a lively method, that achieve the presence methods have two main types: one is based on threedimensional modeling of virtual display, and the others is based on image stitching virtual display[7].

\section{A. Based on three-dimensional modeling of the virtual display design}

Take use of professional modeling software, such as: 3DMAX, MAYA, build three-dimensional and threedimensional objects in the scene model to simulate real-world scenes and objects. With the soaring levels of computer performance and software performance improvement, this modeling approach is an implementation with variety manifestation ability and strong demonstrate ability which can form through the scene and physical modeling, texturing and rendering; simulate real-world scenarios and physical form, material, etc. more accurately and output the animation. 
1) Virtual display design base on image stitching: The image mosaic is relatively simple method to achieve display, due to it based on virtual display is compared with threedimensional modeling technology. It can demonstrate the objects characteristics of each angel through multi-frame images or photographs continuous display mode, use flash or multimedia software to add sound, controls, and other ways to show or hide the control.

\section{B. Target user group preference research and information architecture based on the principles of accuracy}

During design process, firstly according to the user's gender, age, educational level, and other information, then the different user groups .It mainly focused on meeting the user group who are matches with products, finally make a target design for other user group.

In recently stages, it already has a lot of user research methods to determine the target user, generally into two categories, the first methods user can directly involve in, such as questionnaires, focus groups, depth interviews; second methods are the user indirectly involved: web log analysis, professional assessment, task analysis, etc[8].

In this paper it will explain the questionnaire on the target user.

The characteristics of target users are important reference factors for interaction design .Goal-oriented user's questions shall include the following information about the users:

- Motivation: why users using this product, what their inner needs are?

- Priority: which features are the most important or most frequently used?

- Experience: Users commonly operating mode and behavior;

- Situation: the user uses the product on which external environment or personal factors;

- Goal: what users want to get from the product?

- Features: which characteristics that users concerned more about.

- Behavior: how users interact with products and what confusion, hesitation do they have?

- Expectations: the product function do you hope for;

- Avoid: Which features can be canceled in the product;

The network in their purchase decision-making process the most important role in channels that user access to car-related information. Compared with newspapers, television, dealerships and other channels, the network channels have the advantages for convenient query and contrast information and the relevant information are rich and comprehensive.

Accuracy principles performances in the web information architecture are they have integrity content and the user can easily understand the content, operate it with small error rate. In this section will induct and extract information based the target user's needs lists and preferences analysis in previous section, eventually get online car modification page information architecture.
Website information architecture is an organizational structure to identify the product or service provides the information between the information. The main task of information architecture is build an open bridge between user awareness and information, it is the carrier of information and intuitive expression[9]. Web-based virtual display car modification online content structure should include three aspects: the first is user system; second is the virtual display and online conversion system; the third is the management system.

1) A refinement of the user's system function points are as follows:

TABLE II. SYSTEM FUNCTION POINT USERS

\begin{tabular}{|c|c|}
\hline User Information System & Users order system \\
\hline User Login & User Collection \\
\hline User Registration & User scheduled \\
\hline User Basic Information & Order Status \\
\hline Modify information & Order modification \\
& \\
\hline Password Protection & \\
\hline
\end{tabular}

2) Virtual display and online conversion function points are listed below:

TABLE III. FUNCTION POINT OF DISPLAY AND MODIFICATION

\begin{tabular}{|c|c|}
\hline Virtual display & Online modification \\
\hline $360^{\circ}$ automatic rotation & Color change \\
\hline $360^{\circ}$ manual rotation & Replace parts and accessories \\
\hline Angle switching & Replacing interior \\
\hline Parts information & Current modification price \\
\hline Parts display & Modification display \\
\hline Type & Modification favorites \\
\hline selection & Modification contrast \\
\hline & Car book \\
\hline
\end{tabular}

The final function design of virtual display and online modification: 
TABLE IV. FUNCTION POINT OF DISPLAY AND MODIFICATION

\begin{tabular}{|c|c|c|c|c|}
\hline Models & $360^{\circ}$ & online & About me & Parameters \\
\hline select & show & modified & modified & $\begin{array}{c}\text { Configuratio } \\
\text { n }\end{array}$ \\
\hline JMC & Appearance & $\begin{array}{c}\text { Standard } \\
\text { models }\end{array}$ & $\begin{array}{c}\text { Conversion } \\
\text { program }\end{array}$ & $\begin{array}{c}\text { Fashion } \\
\text { version }\end{array}$ \\
& Interior & Color & favorites & Deluxe edition \\
& display & scheme & & \\
& & Accessories & Online & \\
& & refit & booking & \\
& & & My product & \\
& & &
\end{tabular}

3) Management System : Managers ensure the website normal operation, the information for managers including: 1 . the product information to add, delete; 2.the user information management. It is undoubtedly inappropriate for multi-level managers, because this hierarchical approach make the managers workload doubled, managers need is a flat structure with a specific plan, so that all of the information with the adaptation of these structures[10].

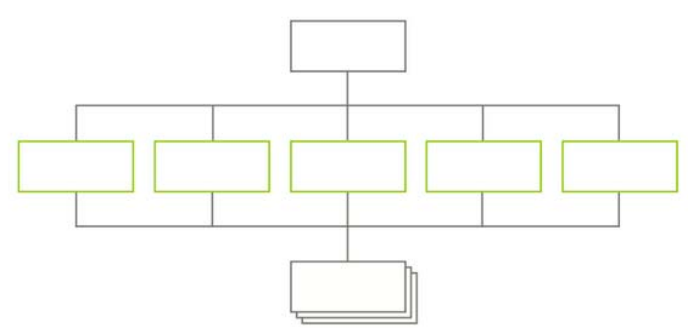

FIGURE II. Flat structure

Oriented managers' functions:

TABLE V. Backstage Management Function Point

\begin{tabular}{|c|c|c|}
\hline $\begin{array}{l}\text { Standard Model } \\
\text { Management }\end{array}$ & $\begin{array}{c}\text { Parts } \\
\text { Management }\end{array}$ & $\begin{array}{c}\text { Order } \\
\text { Management }\end{array}$ \\
\hline View models & Parts Search & Order Confirmation \\
\hline Models added & Parts List & Order analysis \\
\hline Car modification & Accessories add & Order Output \\
\hline Models submitted & Accessories Delete & \\
\hline
\end{tabular}

Change Color Type:

\begin{tabular}{|l||c|c|c|c|}
\hline black $\quad$ red & white & blue & $\begin{array}{c}\text { Silver } \\
\text { gray }\end{array}$ & green \\
\hline
\end{tabular}

Change Accessories Type:

TABLE VI. ACCESSORY MODIFIED TYPE

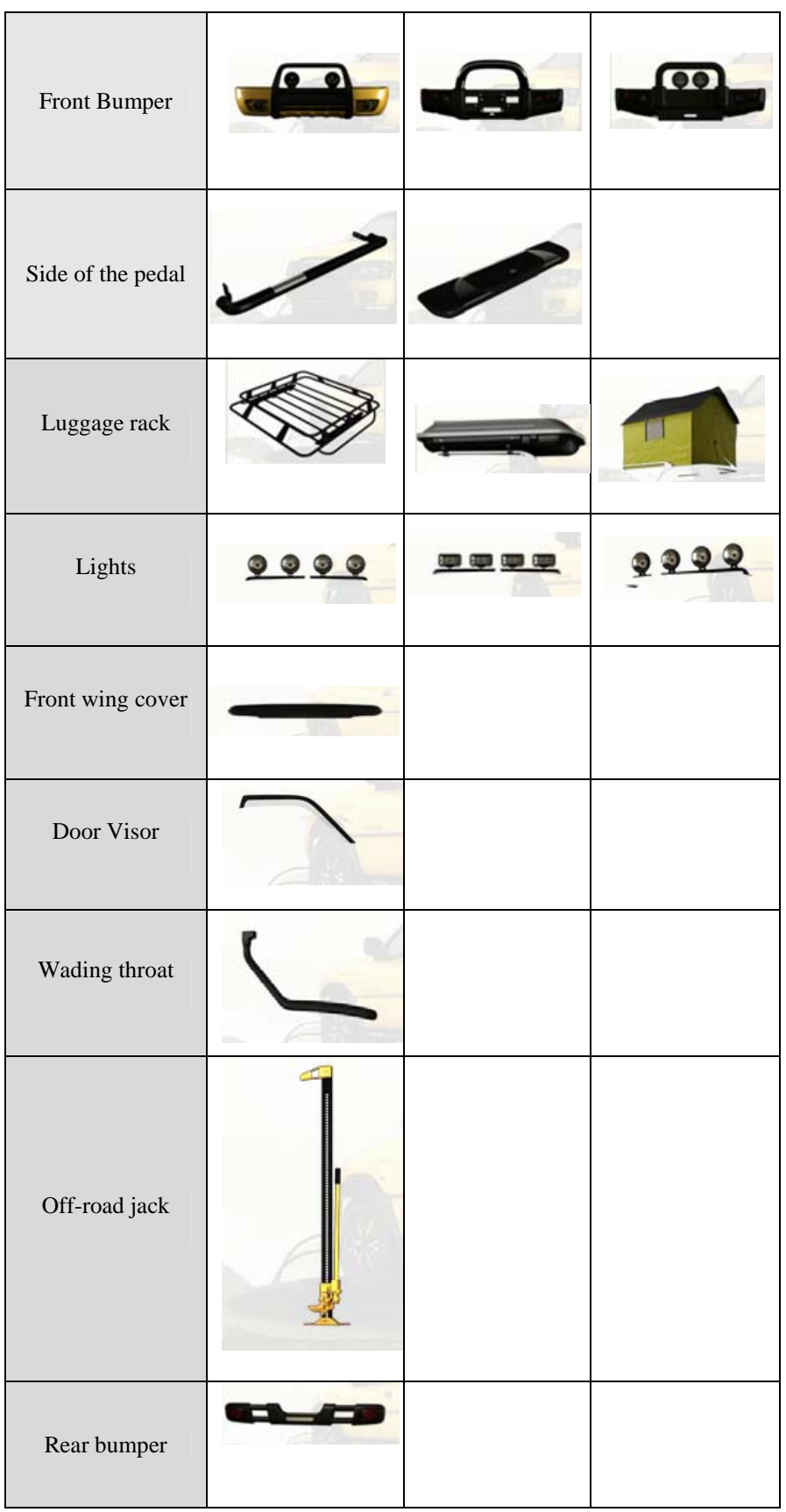

Website Information Architecture:

Based on data analysis of target user groups and preference to summed up the user's functional requirements, under this 
basis, sorting and summed website design function points, then combined with the general features of the site, the overall information architecture of the site are as follows:

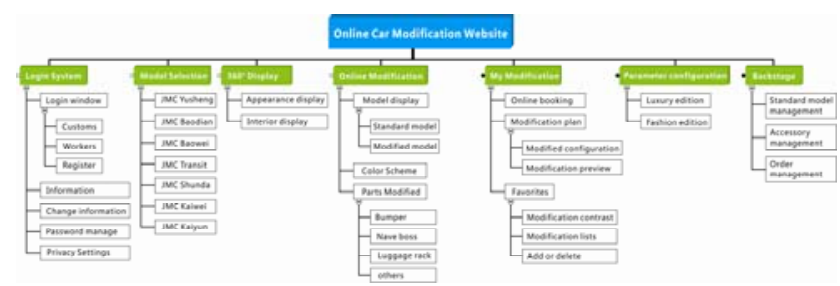

FIGURE III.

Information architecture page of online car modification

\section{Task flow study based on the patency principle}

The page task flow patency in the performance that users can successfully complete website functional tasks that does not lead the stagnation during user experience step. In practice, the introduction of specific design task walkthroughs method with user's tasks as a clue, record user interaction step, through observing and analyzing user interaction, and make process improvements to possible changes, and ultimately complete user mission objectives.

Task flow of online car modification websites:

1) According to the site's architecture can draw conclusion that task starting point is entry into the home, user predefined success as the finished point.

2) The entire process from the main interface to enter the site user predefined can be subdivided into three sub-tasks: Car virtual display tasks; cars online modification tasks; automotive ordering process.

3) Task interaction steps.

Automotive interactive virtual display task step

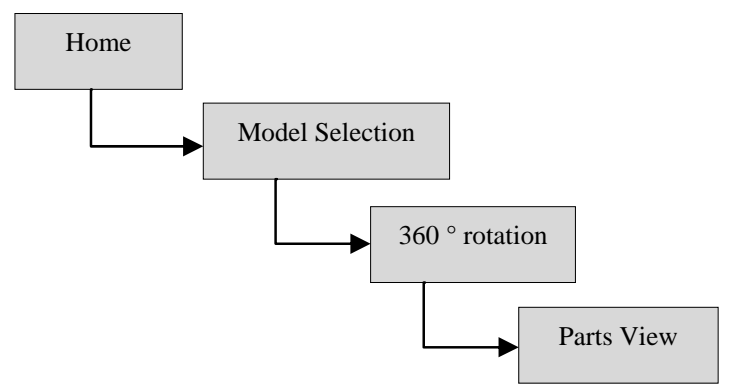

nline car modification task interaction steps

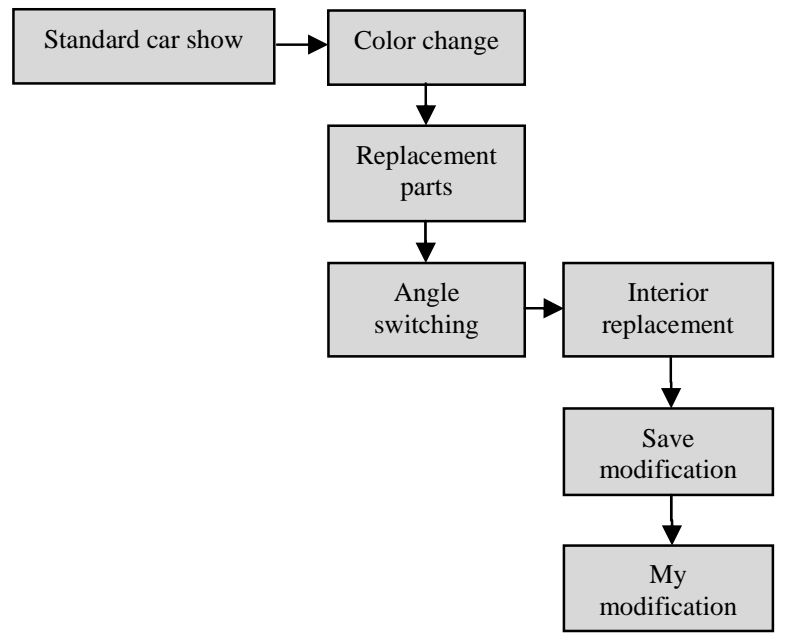

The interactive step of booking car online

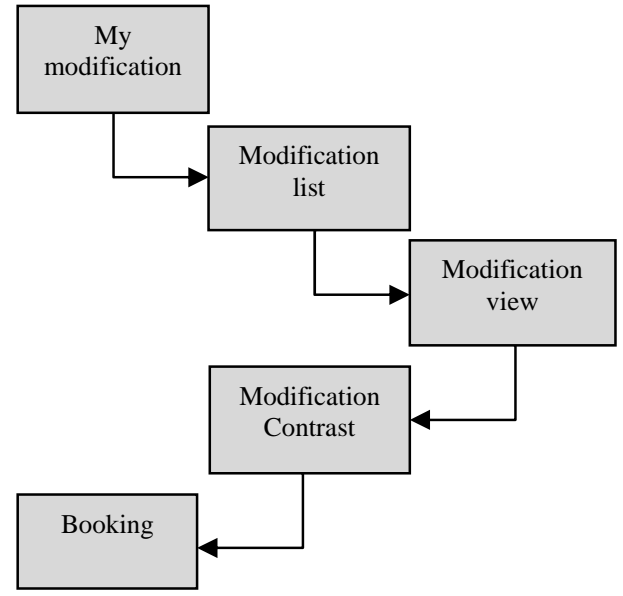

4) possible changes. Optimized interactive processes, and ultimately establish the user's task flow.

Automotive interactive virtual display task step

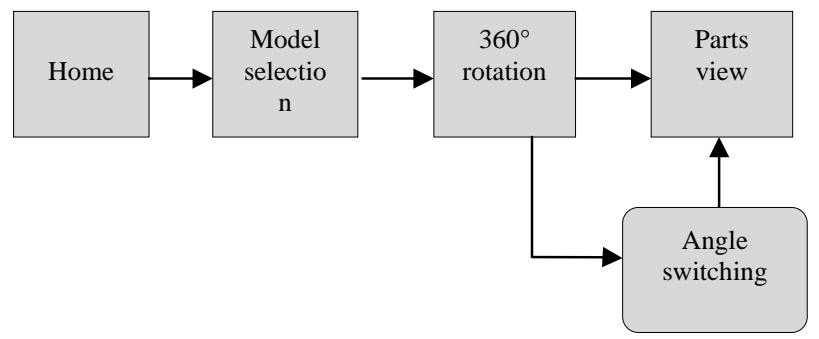

Steps are integrity basically; some users may switch perspective repeatedly.

Online car modification task interaction steps

It is uncertain that the order users replace colors, accessories and interior. After several modify the same type components as well as replacement parts, it starts to modified, the modification steps are as follows: 


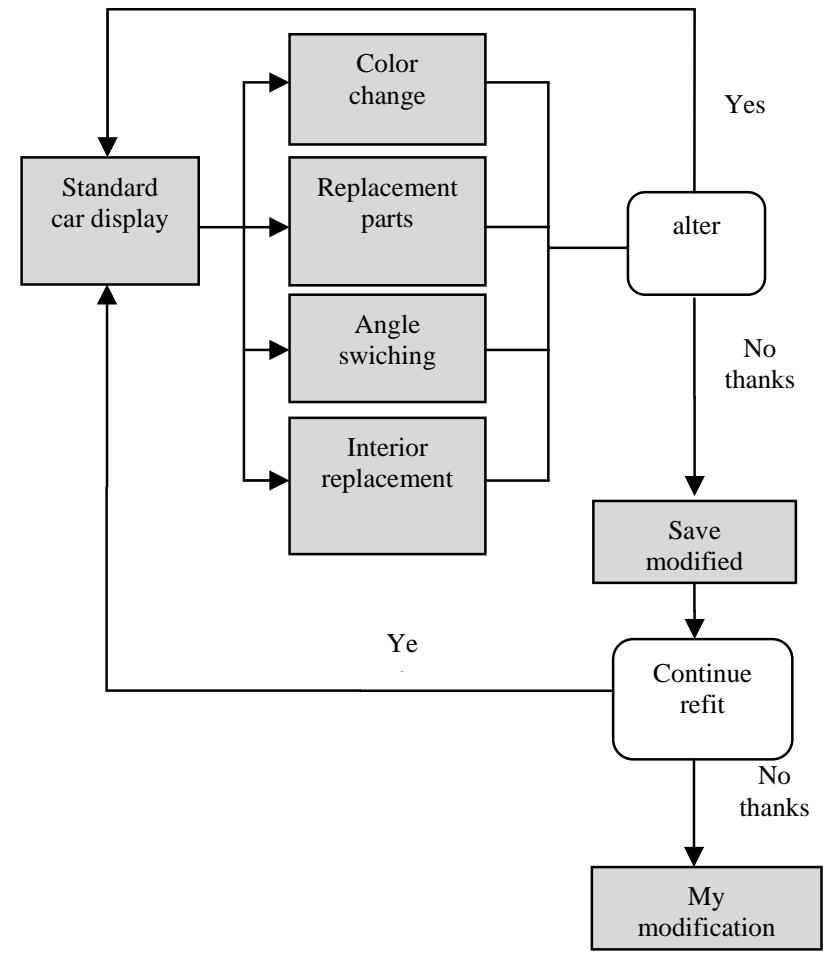

Car online reservation process

Interactive tasks processes only taking into account the logged-on user, the task flow of the user is not logged does not exist. Users have bookmarked modified models direct booking process:

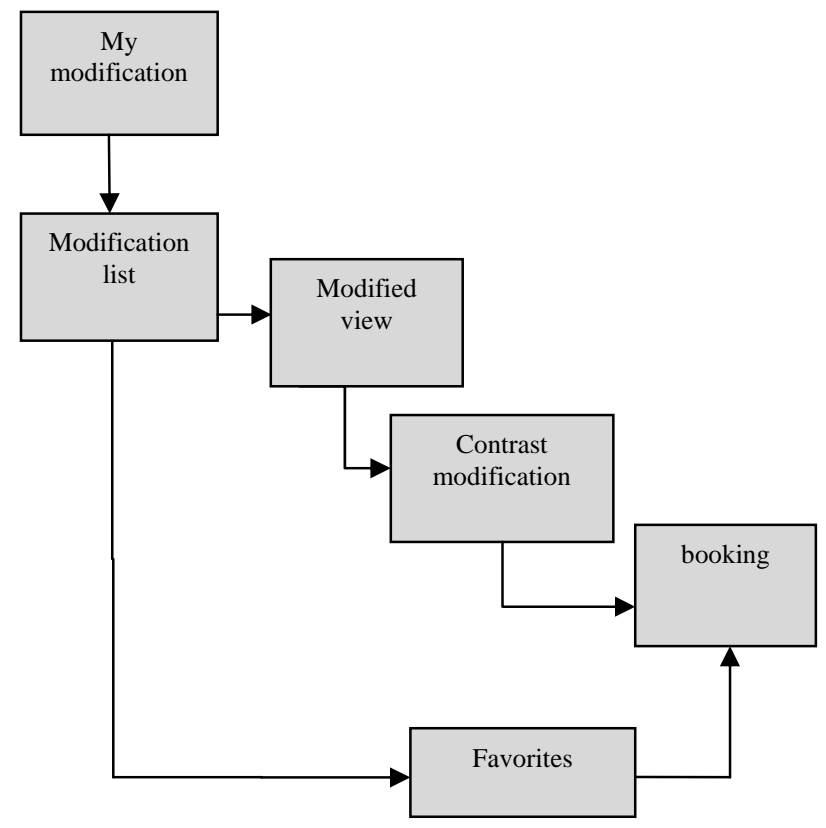

D. Pages layout study based on the consistency principles

Consistency in the page layout model was convergence in real life and virtual operating model, the life of operating experience in the virtual operation can also be applied, to achieve the specific spacing page normative through the grid blocks, components, font size, etc.

Grid system English name for "grid systems", which know and regulate web page layout and information distribution through regular grid array. This layout is developed from a flat grid system[11]. Under the guidance of grid system, the size of the components in the page there is a pattern, so that the page can greatly increase the normative. Grid-based design that allows the layout of each page throughout the site keeps consistent and increase page's similarity, thus reducing learning costs and enhances the user experience[12]. While page layout reducing the workload of the design greatly, it is standardized and reusable.

To model management page as an example:

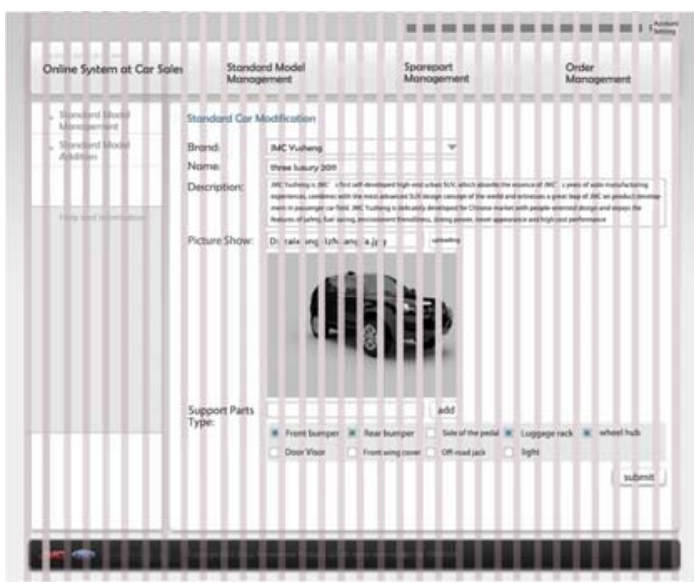

FIGURE IV.

Model Management grid page

Page are divide by 34 width of 30px grid cells, in which the grid spacing to $10 \mathrm{px}$;

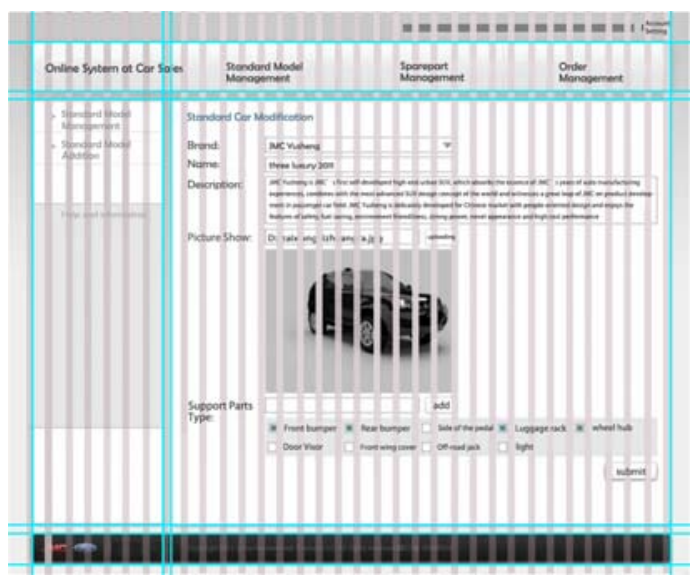

FIGURE V. Model Management page divided by grid

Overall page layout to landscape can be divided into three: the middle block is called two rows; intermediate grid is 7 blocks on the left, the right side is 27; block space is10px grid gap. While the grids also standardize the text block's edge 
distance, the width of text, table block, and the spacing between icons and text.

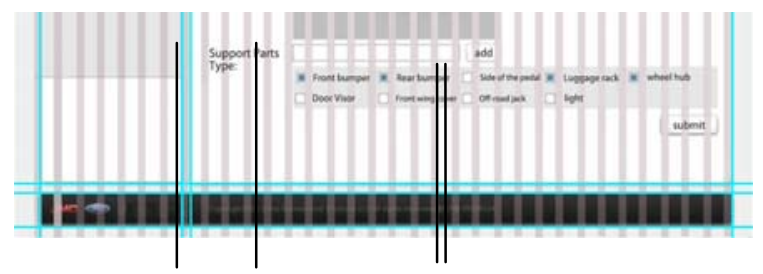

FIGURE VI. Details of model management grid page

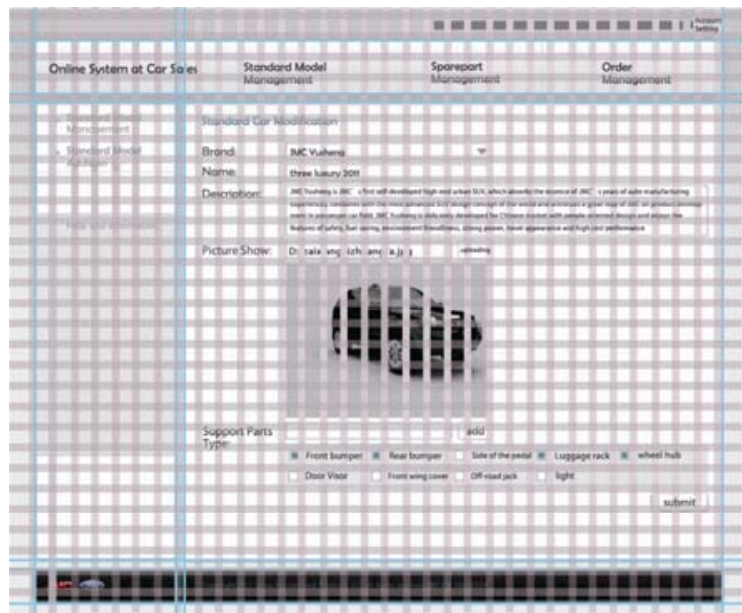

FIGURE VII. Vertical and horizontal grid

Horizontal grid identifies the height of top navigation bar, the footer bar at bottom; carve out of the spacing between each block. However, the high level cannot be completely rasterized due to the uncertainties of intermediate block in each page.

\section{E. Interaction design details}

Interaction details design needs to be designed each component and details one by one, then complete special effects and visual elements of the design, is the last step of page design.

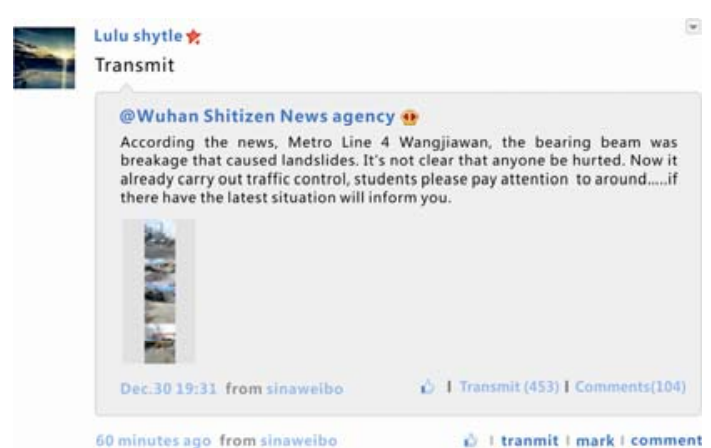

FIGURE VIII.

Before mouse over
Lulu shytle

Transmit

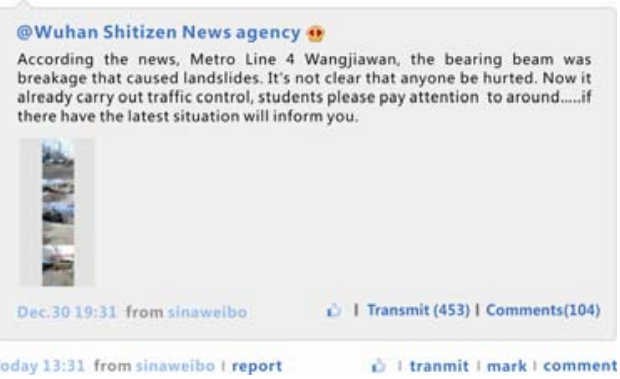

FIGURE IX.

After mouse over

$360^{\circ}$ Virtual showcase angle switching display using the mouse over and click trigger this asymptotic expansion in the form, the appearance of the page as the default display, then mouse over the button, the button is stretched to form a complete angle switching components.

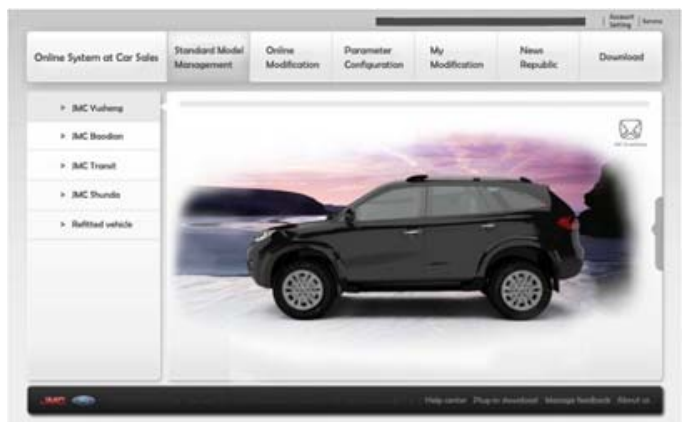

FIGURE X. Before switching

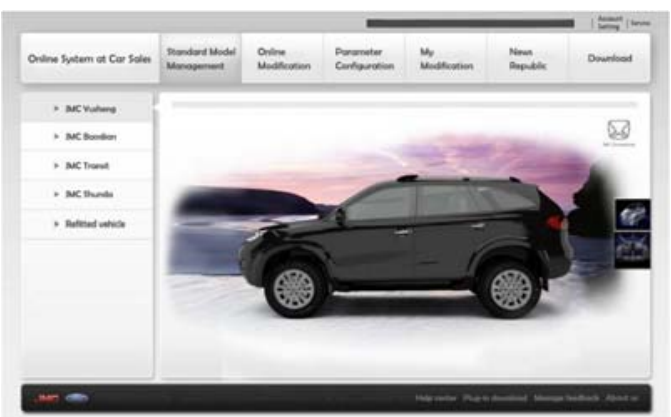

FIGURE XI. After mouse over

Login systems and parts modified navigation bar information are using a mouse click trigger form to ensure less interfere with the normal display processes during the process of the mouse over on the page. 


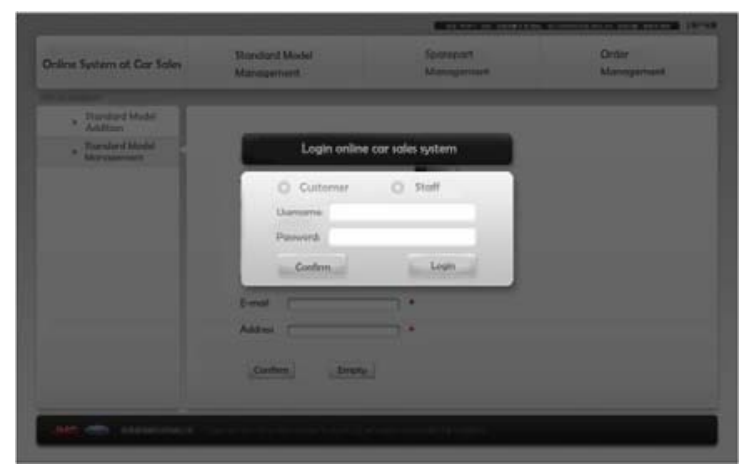

FIGURE XII. $\quad$ login in

Web final design :

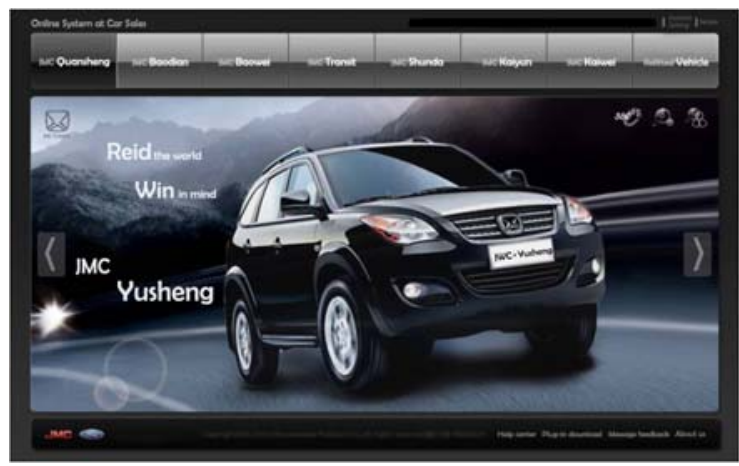

FIGURE XIII. Home Interface

\section{CONCLUSION}

In all, after compare and analyze interactive virtual display designs, it comes to the conclusion their three principles: accuracy, patency and consistency. Accuracy principles used to guide the site's information construction, patency principles used to guide the task flow, the consistency principle to guide page builder, and are separately pointed out instructional methods and paths. It puts a specific analysis on the online modified car interactive design website based on virtual showcase interactive design model method. Established website information architecture through analysis the target user groups and theirs preferences, then base on mission walkthroughs methods to analyze websites task flow, on the condition that user's mental model of and realistic model keep consistency to design the website interface layout and interactive form, verify interactive virtual showcase theoretical model of the design is reasonable and feasible to some extent.

\section{REFERENCES}

[1] Fu Xing. The Study of Interactive Multimedia Technology in Display Design [D]. Tianjin Academy of Fine Arts 2009.

[2] [2] Du Wenwen. WYSIWYG mode on the phone side usability studies [D]. Zhejiang University2011.

[3] PREECE J,ROGERS Y,SHARP H.Interaction Design: Beyond humancomputer interaction. . 2002.

[4] Nelson. Usability engineering, Liu zheng jie Beijing: Mechanical Industry Press, 2004.

[5] Zhong Ming. Interactive Design Objectives Based on User Task Analysis Methods and Processes [D]. Hunan University , 2009

[6] Cooper A. About face: The essentials of user interface design. John Wiley \& Sons, Inc. New York, NY, USA, 1995.

[7] Yan beginnings. Virtual Experimental Design Study Based on the Irrational User Model [D]. Jilin University , 2011.

[8] Party Joy. User Research Method and Application Based on Social Network Analysis [D]. Shandong University 2011.

[9] Liu mind, Shen Cheung Hing. Determinants Website Information Architecture [J]. Information Science. 2007(02)

[10] Christos Katsanos,Nikolaos Tselios.Automated Semantic Elaboration Of Web Site Information Architecture[J]. Interacting with Computers . 2008

[11] Pahl G, Beitz W. Engineering design: a systematic approach. Springer, 1996

[12] Jennifer Preece, Yvonne Rogers. Interaction Design: Beyond HumanComputer Interaction, Beijing: Electronic Industry Press, 2003.

[13] BAO Hu. Introduction of virtual reality technology [J]. Chinese Basic Science 2003 (03)

[14] Hu Changping, Deng Shengli. Website Information Architecture Elements and Model Analysis Based on the User Experience [J]. Information Science 2006 (03)KAUFMANN H,MEYER B.Simulating educational physical experiments in augmented reality. Proceedings of SIGGRAPH Asia'08:ACM SIGGRAPH Asia 2008 Educators Programme . 2008

[15] Daniel Shiffman.Learning Processing: A Beginner's Guide to Programming Images, Animation, and Interaction. . 2008

[16] Liu Tao, Qi Jing. Car Modification Industry Development status, Problems and Countermeasures [J]. Automobile \& Parts. 2008(37)

[17] Card, S. K.,Moran, T. P.,Newell, A.The Psychology of HumanComputer Interaction. Applied Ergonomics . 1984 